\title{
SURFACE COMPOSITION AND NANO-MECHANICAL PROPERTIES OF HUMAN ENAMEL BRUSHED WITH TOOTHPASTE STANDARDIZED BY 10 Wt. \% NANO-HYDROXYAPATITE
}

\author{
Dalia M Abdel-Hamid *, Norhan A El-Dokky ** and Sherif B El-Tawil **
}

\begin{abstract}
Purpose: Evaluation of the effect of simulated brushing with toothpaste standardized by 10 wt. \% nano-hydroxyapatite (n-HAp) for one year on the surface composition and nano-mechanical properties (hardness and elastic modulus) of human enamel.

Study design: 20 sliced human enamel/dentin slabs were divided into: control group (brushed with a commercial toothpaste) and test group (brushed with the same toothpaste with $10 \mathrm{wt}$. \% $\mathrm{n}$-HAp $20 \mathrm{~nm}$ ). Brushing was performed for one hour/day for 24 days. The nano-hardness and elastic modulus were measured (GPa) by the nano-indenter. SEM and EDXA were performed to study the morphology, thickness and the chemical composition of enamel surface. $\mathrm{The} \mathrm{Ca} / \mathrm{P}$ ratio was calculated (at. \%). The data were statistically analyzed.
\end{abstract}

Results: Insignificant difference $(P=0.070$ ) between the nanohardness values of the 2 groups was obtained. However, the elastic modulus of the control group was significantly lower than that of the test group $(P=0.019)$. SEM of the test group revealed the precipitation of n-HAp layer $(\sim 5$ $\mu \mathrm{m}$ thick). The $\mathrm{Ca} / \mathrm{P}$ ratios and the other minerals of the two groups were not significantly different.

Conclusions: Using dental products containing $\geq 10$ wt. \% n-AHp should be restricted to patients susceptible to demineralization; to avoid their detrimental effect on the elastic modulus that could be negatively reflected clinically on the mechanical behavior of the teeth.

KEYWORDS: Surface composition; Nano-mechanical; Enamel; Nano-hydroxyapatite; Brushing; Toothpaste

* Assistant Professor of Dental Materials Science, Biomaterials Department, Faculty of Dentistry, Cairo University, Egypt.

** Assistant Professor of Pedodontics, Pediatric and Community Dentistry Department, Faculty of Dentistry, Cairo University, Egypt 


\section{INTRODUCTION}

Hydroxyapatite is the main biomineral component present in human hard tissues. It can be synthesized artificially with the same chemical composition and crystalline structure of the hydroxyapatite found in teeth and bones ${ }^{1}$. It has attracted much of interest due to its excellent biological behavior as being biocompatible, bioactive, non-toxic and non- inflammatory ${ }^{2,3}$. Nano-hydroxyapatite (n-HAp) is a revolutionary material that gained wide acceptance in dentistry in recent years. It is a good source of free $\mathrm{Ca}$ which is the key element for remineralization, protection against caries and dental erosion ${ }^{4}$. Nowadays, several studies revealed high remineralization potential of n-HAp containing toothpastes ${ }^{5-7}$.

Currently, a material that can entirely replace human teeth in terms of their biological and mechanical properties has not yet been found. Human teeth have better mechanical properties and superior biocompatibility than all dental restorative materials including: synthetic resins, ceramics and dental alloys. Understanding the various mechanical properties of human teeth is the basis of dental restorative materials research. Moreover, it can provide a reference for developing and assessing the mechanical properties of new dental materials ${ }^{8}$.

The mechanical properties of human teeth are determined by their chemical composition and structure. The mechanical properties of teeth include elasticity, hardness, visco-elasticity and fracture behavior ${ }^{9}$. Elasticity is a term used to define the characteristic in which a material changes under external force and recovers after force removal. The elastic property indices of natural teeth mainly include: the elastic modulus i.e. Young's modulus (ratio of normal stress to normal strain up to the proportional limit), shear modulus (ratio of shear stress to shear strain up to the proportional limit) and Poisson's ratio (ratio of transverse contraction strain to longitudinal extension strain in the direction of the stretching force within the elastic range of the material). However, the elastic modulus is the property that has been studied most extensively ${ }^{10}$.

Hardness is a mechanical property that measures the ability of a solid material to resist scratching, indentation and penetration. Measurements of the hardness of natural teeth have been shifted from macroscopic to microscopic and recently to nanoscopic scale. These advanced methods and instruments enabled the accurate measurement of hardness at different sites of even an enamel rod ${ }^{10}$.

Today, n-HAp containing toothpastes are commercially available. Owing to their high potential for repairing minor dental enamel defects and decreasing dentin hypersensitivity ${ }^{4,5,7}$, the use of n-HAp containing toothpaste are increasing. However, few data are available for the effect of their prolonged use on surface composition and the nano-mechanical properties of human enamel, which could affect its surface properties and its ease of restorability or even its behavior under force. Therefore, the purpose of this study was to evaluate the effect of simulated brushing with toothpaste standardized by 10 wt. \% nanohydroxyapatite (n-HAp) powder for one year on the surface composition and nano-mechanical properties (hardness and elastic modulus) of human enamel. The null hypothesis was that there would be no statistically significant difference in the surface composition and nano-mechanical properties (hardness and elastic modulus) of human enamel after the simulated brushing with toothpaste standardized by n-HAp (10 wt. \%) for one year.

\section{MATERIALS AND METHODS}

\section{Teeth selection and preparation}

For sample size calculation, a pilot study has been done using 5 specimens in each of the control and test groups. According to the obtained results, the sample size was calculated. Based upon the 
measured elastic modulus, the effect size was 1.54. Using an alpha $(\alpha)$ level of $(5 \%)$ and Beta $(\beta)$ level of 0.20 i.e. power $=80 \%$; the predicted minimum sample size (n) was 7 specimens in each group. However, 10 specimens were used for each group to overcome the limitations of the nanoindentation test. Sample size calculation was performed using G*Power software Version 3.1.9.2

The experimental study was carried out in accordance with the ethical guidelines in research with human participants and approved by the Research Ethics Committee of the Faculty of Dentistry, Cairo University (Code 16-9-19). These ethical guidelines are in full accordance with the World Medical Association Declaration of Helsinki.

A total of 10 sound human permanent premolar teeth were used to prepare 20 enamel/dentin slab specimens. All teeth were extracted as required for orthodontic treatment from Egyptian children (Pedodontics Department, Faculty of Dentistry, Cairo University). Before extraction, a written informed consent was signed by the parents of all participants in order to collect the teeth. The obtained written consent was approved by the Research Ethics Committee of the Faculty of Dentistry, Cairo University. The age of the patients ranged from 10-14 years. The freshly extracted teeth were thoroughly cleaned of debris and inspected under a stereomicroscope (Leica applicator suite, version 3.1.0, Leica Microsystems, Switzerland) for visibly observable cracks, hypoplasia or white spot lesions, and then stored in $4{ }^{\circ} \mathrm{C}$ physiologic saline solution until required.

The crowns were separated from the roots by a diamond-coated band saw under water condition (Struers Minitom; Struers, Copenhagen, Denmark). Enamel/dentin slabs $(3 \mathrm{~mm} \times 3 \mathrm{~mm})$ were prepared from the buccal and lingual surfaces of each premolar tooth and embedded in a chemicallycured polymethyl methacrylate (Acrostone, Egypt) blocks. The superficial enamel surface was ground flat with water-cooled carborundum discs (1200 grit; Water Proof Silicon Carbide Paper, Struers, Germany) and polished with diamond paste $(15 \mu \mathrm{m}$ Diamond Paste, Struers) ${ }^{5}$.

The 20 enamel/dentin slabs obtained from the 10 teeth (buccal and lingual enamel/dentin slab/tooth) were randomly divided in to 2 groups: control and test groups. Each tooth slab was allocated in one group. The order of specimen's allocated to groups was determined using a computer generated random sequence table (randomn.org) which was performed by one of the authors other than the one prepared the specimens.

\section{Nano-hydroxy apatite (n-HAp) toothpaste preparation and simulated tooth brushing}

Nano-hydroxyapatite powder (n-HAp) was purchased with size range of 10-20 nm (Fig. 1) as obtained from the manufacturer (Nanostreams Egypt, batch no NS 0012). The used n-HAp powder has similar crystallinity to apatite in bone and enamel with $\mathrm{Ca} / \mathrm{P}$ ratio of 1.67 as stated by the manufacturer.

A commercially available toothpaste (Signal Kids, Unilever Mashreq-Personal Care Company, Egypt) was used in the current study and served as a control group. For the test group, the standardized toothpaste was prepared by adding $10 \mathrm{wt}$ \% n-HAp

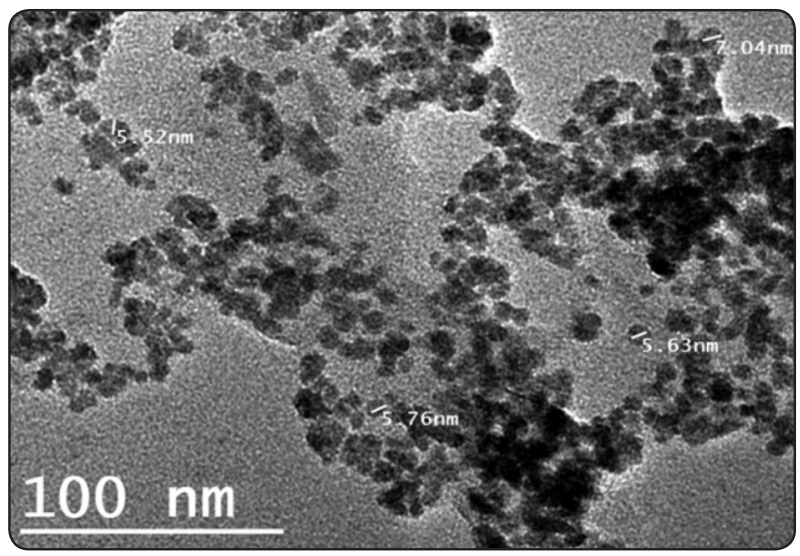

Fig. (1) TEM of n-HAp powder (Nanostreams Co. Cairo, Egypt) 
power to the commercial toothpaste ${ }^{5}$. In accordance with EN ISO 11609 (European standards for preparing artificial saliva/toothpaste slurries), each toothpaste was diluted in 3 parts (1:3) by volume to attain a homogeneous slurry ${ }^{7}$. The artificial saliva was prepared according to the following composition: $\mathrm{NaCl}(0.4 \mathrm{~g}), \mathrm{KCl}(0.4 \mathrm{~g}), \mathrm{NaH}_{2} \mathrm{PO}_{4} \cdot 2 \mathrm{H}_{2} \mathrm{O}(0.78 \mathrm{~g})$, $\mathrm{Na}_{2} \mathrm{~S} \bullet 9 \mathrm{H}_{2} \mathrm{O}(00.5 \mathrm{~g})$, urea $(1 \mathrm{~g}), \mathrm{CaCl}_{2} \cdot 2 \mathrm{H}_{2} \mathrm{O}(0.795$ $\mathrm{g})$, distilled water $(1000 \mathrm{ml}){ }^{11}$.

Each enamel/dentin slab specimen was mounted with a special attachment to a tooth brushing holder device. Tooth brushing was accomplished with an electric brush (Oral-B, Cross action Power Max with medium bristle stiffness) under a weight of $200 \mathrm{~g}$ for 1 hour/day for 24 days $^{12}$. Freshly prepared toothpaste/slurries were prepared every day for 24 days. After each brushing, the specimens were rinsed with distilled water, until all the remnants of the toothpaste/artificial saliva slurry were removed ${ }^{7}$. Then the specimens were stored in the distilled water until next brushing.

The $\mathrm{pH}$ value of the artificial saliva was 7.0 while the $\mathrm{pH}$ value of both freshly prepared slurries (commercial toothpaste/artificial saliva and the 10 wt.\% n-HAp standardized toothpaste/artificial saliva) was 6.3 as measured by the $\mathrm{pH}$ meter (pHep, Pocket-sized pH Meter, Hanna instrument, Rhode Island, USA). Additionally, the $\mathrm{pH}$ was measured during the whole brushing hour.

\section{Measurement of the nano-mechanical properties of enamel}

Nanoindentation testing was accomplished under dry conditions, in accordance with previous studies $^{9,13}$. Berkovich diamond tip with a nanoindenter (XP, MST System Corp., Oak Ridge, NT, USA) was used. The indents were done using a force controlled test load of $20 \mathrm{mN}$ at a rate of $10 \mathrm{~nm} / \mathrm{sec}$ onds at room temperature. The time of loading was
15 seconds reaching indentation average depth of $500 \mathrm{~nm}^{13,14}$. Each enamel/dentine slab specimen was subjected to 9 indents. The method described by Oliver and Pharr ${ }^{15}$ was followed to calculate the hardness $(\mathrm{H})$ and elastic modulus of enamel (E), using the formula $\mathrm{H}=\mathrm{P}_{\text {max }} / \mathrm{A}_{c}$, where, $\mathrm{P}_{\text {max }}$ is peak load and $\mathrm{A}_{c}$ is the contact area; and the formula 1/ $\mathrm{E}_{\mathrm{r}}=\left(1-v^{2}\right) / \mathrm{E}+\left(1-v_{\mathrm{i}}^{2}\right) / \mathrm{E}_{\mathrm{i}}$, where $\mathrm{E}$ and $v$ are elastic modulus and Poisson's ratio for the specimen and $\mathrm{E}_{\mathrm{i}}$ and $v_{\mathrm{i}}$ are the same parameters for the indenter. The hardness and the elastic modulus values were reported in GPa. Poisson's ratio for enamel was assumed to be 0.33 .

\section{Scanning electron microscopy (SEM) imaging}

Representative specimens were randomly selected to study the morphology and the thickness of the newly precipitated layer of n-HAp. The specimens were sputter-coated with gold for 1.5 minutes. Microscopic examination of the specimens was performed by the scanning electron microscope (SEM), (Model Quanta 250 FEG (Field Emission Gun) with accelerating voltage $30 \mathrm{KV}$. FEI Company, Netherlands). Top views were obtained and then the specimens were cut vertically and sputter coated again for side view examination.

\section{Energy dispersive x-ray analyses (EDXA)}

The chemical composition of enamel surface for 3 randomly selected specimen from the control group and their corresponding test group (lingual and buccal halves of each tooth) was performed with the same SEM fitted with the energy dispersive $\mathrm{X}$-ray analyses (EDX), using accelerating voltage $30 \mathrm{~K}$.V., magnification14x up to 1000000 and resolution for Gun.1n). The readings were then converted to $\mathrm{Ca} / \mathrm{P}$ ratio using the atomic percentage (at. \%) to estimate the alteration in the mineral density of the enamel surface. 


\section{Statistical analysis}

Numerical data were explored for normality by checking the distribution of data using KolmogorovSmirnov and Shapiro-Wilk normality tests. All the results of the tested properties (surface composition, nanohardness and enamel elastic modulus) showed non-parametric distribution. The Mann-Whitney $\mathrm{U}$ test was used to compare the atomic percentage (at. \%) of the different minerals as well as the $\mathrm{Ca} / \mathrm{P}$ ratio, nanohardness and the elastic modulus of brushed enamel surface in the 2 groups. All data were presented as median and range values. The significance level was set at $\mathrm{P} \leq 0.05$. Statistical analysis was done with IBM (IBM ${ }^{\circledR}$ Corporation, NY, USA) SPSS ${ }^{\circledR}$ (SPSS, Inc., an IBM Company) Statistics Version 20 for Windows.

\section{RESULTS}

\section{Nanohardness and elastic modulus of enamel}

The results revealed that there was no statistically significant difference $(P$-value $=0.070)$ between the nanohardness values (GPa) of the enamel specimen's brushed with the plain commercially available toothpaste (control group) and the 10 wt. \% n-HAp standardized toothpaste (test group) as seen in table (1). On the other hand, there was a statistically significant difference between the values of the enamel elastic modulus $(\mathrm{GPa})$ of the 2 groups $(P$-value $=0.019)$. Where, the control group revealed statistically significant lower mean enamel elastic modulus value ( $\mathrm{GPa}$ ) than the test group as shown in table (2).

TABLE (1) Mann-Whitney U test for comparison between the enamel nanohardness (GPa) in the 2 groups

\begin{tabular}{lcccc}
\hline Group & $\begin{array}{c}\text { Median } \\
(\mathbf{G P a})\end{array}$ & $\begin{array}{c}\text { Minimum } \\
(\mathbf{G P a})\end{array}$ & $\begin{array}{c}\text { Maximum } \\
(\mathbf{G P a})\end{array}$ & $\boldsymbol{P}$-value \\
\hline Control & 2.4 & 1.1 & 5.5 & 0.070 \\
Test & 4.2 & 3.0 & 8.6 & \\
\hline
\end{tabular}

*: Significant at $P \leq 0.05$
TABLE (2) Mann-Whitney $U$ for comparison between the values of the enamel elastic modulus (GPa) in the 2 groups

\begin{tabular}{lcccc}
\hline Group & $\begin{array}{c}\text { Median } \\
(\mathbf{G P a})\end{array}$ & $\begin{array}{c}\text { Minimum } \\
(\mathbf{G P a})\end{array}$ & $\begin{array}{c}\text { Maximum } \\
(\mathbf{G P a})\end{array}$ & $\boldsymbol{P}$-value \\
\hline Control & 92.6 & 48.9 & 118.1 & \\
Test & 117.5 & 89.5 & 143.1 & $0.019^{*}$ \\
\hline
\end{tabular}

*: Significant at $P \leq 0.05$

\section{Scanning electron microscopy (SEM) imaging}

The top view seen by the scanning electron (SE) micrograph of the brushed enamel surface of the test group revealed the precipitation of n-HAp layer with particle size range of 14.57-84.69 nm (Fig. 2). On the other hand, the SE micrograph of the brushed enamel surface of the control group revealed a homogenous surface (Fig. 3). Additionally, the side view of the brushed enamel surface of the test group exhibited an average thickness $(\sim 5 \mu \mathrm{m})$ of the newly precipitated n-HAp layer (Fig. 4), while the underlying biological enamel appeared more homogenous as compared to the overlying layer. At higher magnification of the side view, the SE micrograph of the brushed enamel surface of the test group revealed the precipitation of a layer

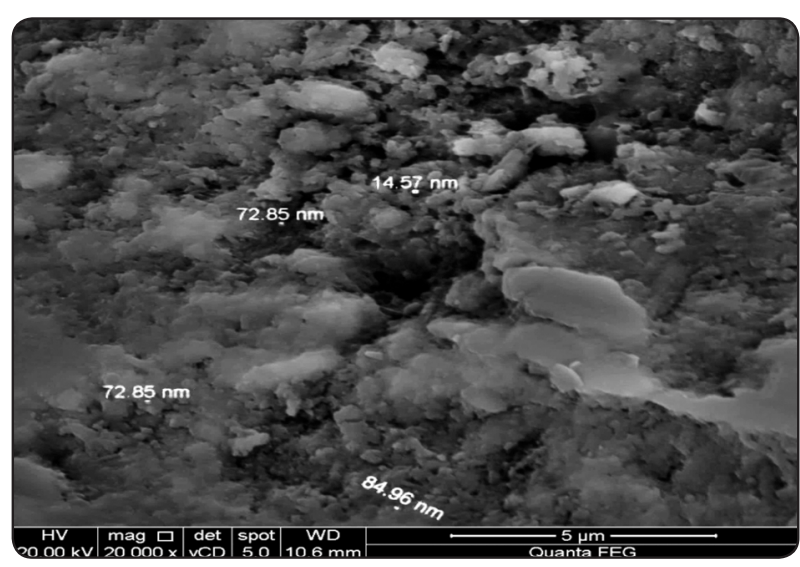

Fig. (2) SE micrograph of the brushed enamel surface of the test group revealing the precipitation of n-HAp layer with particle size ranging from 14. 57- $84.69 \mathrm{~nm}$ (top view). 
of needle like crystal of n-HAp with an average diameter range of 36.43-51.51 nm and length of 257.5-381.8 nm (Fig. 5). While, the SE micrograph of the brushed enamel surface of the control group revealed the presence of ill-defined layer of needle like crystal of n-HAp (Fig. 6)

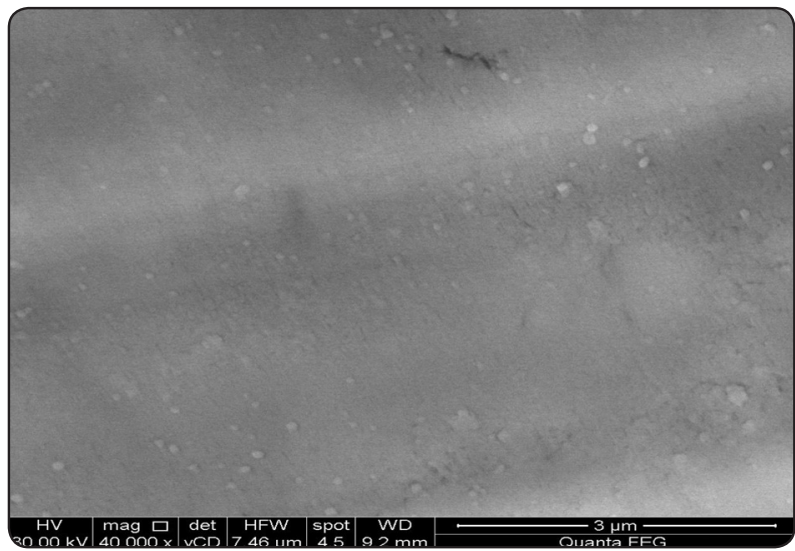

Fig. (3) SE micrograph of the brushed enamel surface of the control group revealing a homogenous surface (top view)

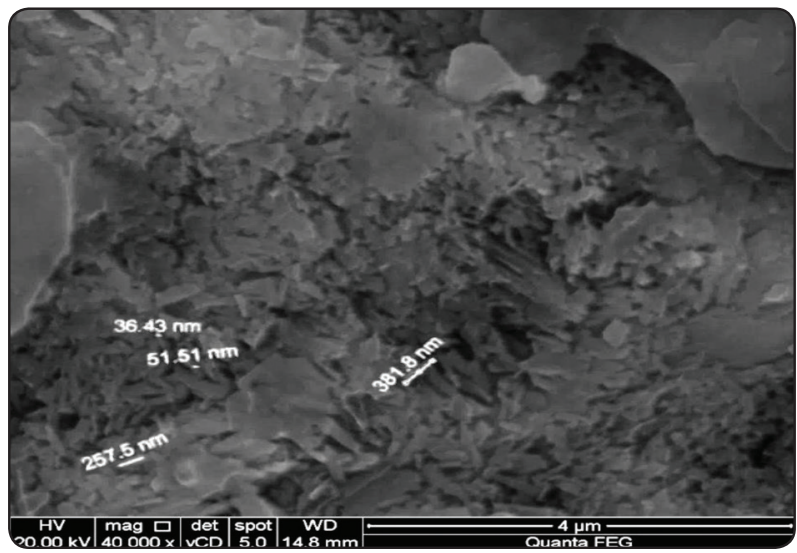

Fig. (5) SE micrograph of the brushed enamel surface of the test group revealing the precipitation of a layer of needle like crystal of n-HAp with an average diameter range of $36.43-51.51 \mathrm{~nm}$ and length of 257.5-381.8 $\mathrm{nm}$ (side view).

\section{Energy dispersive x-ray analyses (EDXA)}

The statistical analysis of the results obtained from the EDXA for enamel surface composition revealed that there was no statistically significant difference between the at. \% of the different minerals and the $\mathrm{Ca} / \mathrm{P}$ ratio in the 2 groups (Table 3 )

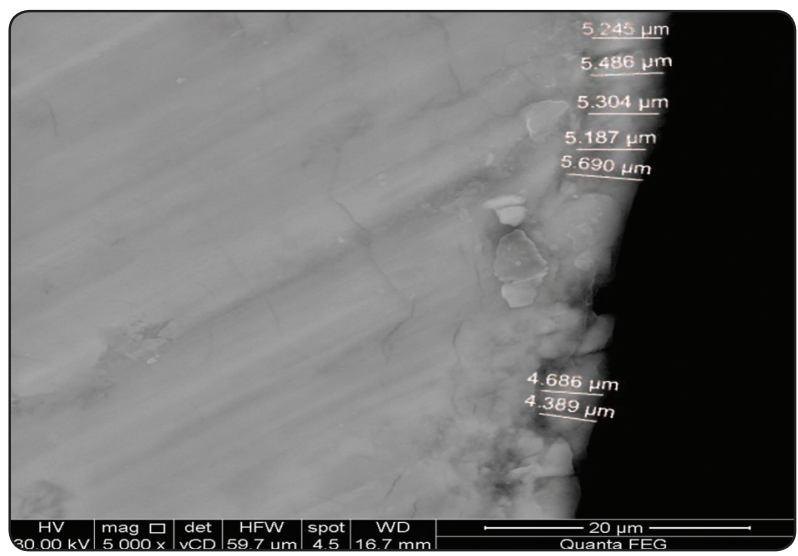

Fig. (4) SE micrograph of the brushed enamel surface of the test group revealing an average thickness $(\sim 5 \mu \mathrm{m})$ of the precipitated n-HAp layer (side view). The underlying biological enamel appeared more homogenous as compared to the newly precipitated layer.

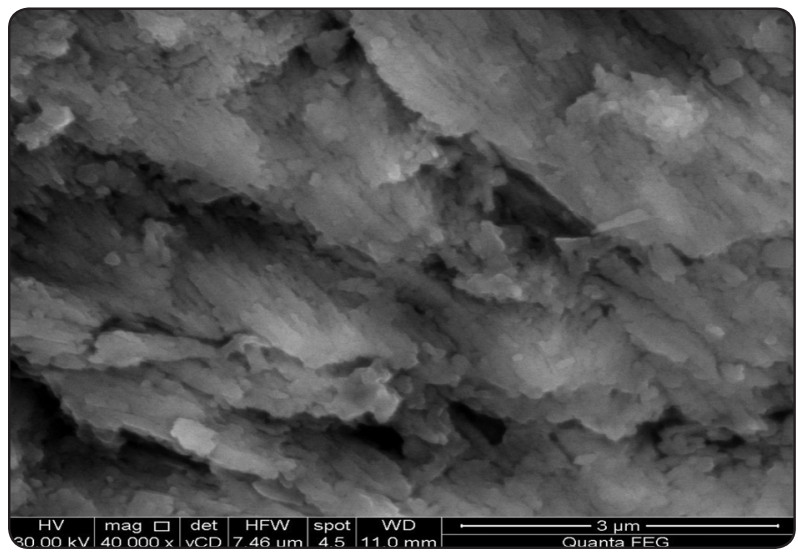

Fig. (6) SE micrograph of the brushed enamel surface of the control group revealing the presence of ill-defined layer of needle like crystal of n-HAp (side view). 
TABLE (3) Mann-Whitney U test for comparison between atomic percentage (at. \%) of the different minerals in the 2 groups

\begin{tabular}{|c|c|c|c|c|c|}
\hline Element & Group & $\begin{array}{c}\text { Median } \\
\text { (at.\%) }\end{array}$ & $\begin{array}{c}\text { Minimum } \\
\text { (at. \%) }\end{array}$ & $\begin{array}{c}\text { Maximum } \\
\text { (at. \%) }\end{array}$ & $P$-value \\
\hline \multirow{2}{*}{$\mathrm{Ca}$} & Control & 28.26 & 24.17 & 29.32 & \multirow{2}{*}{0.400} \\
\hline & Test & 24.71 & 21.29 & 25.70 & \\
\hline \multirow{2}{*}{$\mathbf{P}$} & Control & 18.25 & 15.16 & 18.26 & \multirow{2}{*}{0.100} \\
\hline & Test & 14.26 & 14.10 & 15.00 & \\
\hline \multirow{2}{*}{ Ca:P ratio } & Control & 1.59 & 1.55 & 1.61 & \multirow{2}{*}{0.700} \\
\hline & Test & 1.71 & 1.51 & 1.73 & \\
\hline \multirow{2}{*}{ C } & Control & 17.36 & 16.85 & 19.57 & \multirow{2}{*}{0.100} \\
\hline & Test & 21.16 & 20.07 & 29.04 & \\
\hline \multirow{2}{*}{$\mathbf{O}$} & Control & 35.17 & 33.51 & 39.60 & \multirow{2}{*}{1.000} \\
\hline & Test & 37.47 & 30.51 & 41.65 & \\
\hline \multirow{2}{*}{$\mathrm{Na}$} & Control & 0.75 & 0.75 & 0.82 & \multirow{2}{*}{0.700} \\
\hline & Test & 0.88 & 0.39 & 1.02 & \\
\hline \multirow{2}{*}{ Mg } & Control & 0.26 & 0.20 & 0.26 & \multirow{2}{*}{0.200} \\
\hline & Test & 0.36 & 0.26 & 0.79 & \\
\hline \multirow{2}{*}{$\mathbf{S i}$} & Control & 0.21 & 0.13 & 0.22 & \multirow{2}{*}{0.400} \\
\hline & Test & 0.26 & 0.19 & 0.46 & \\
\hline \multirow{2}{*}{ Cl } & Control & 0.29 & 0.25 & 0.38 & \multirow{2}{*}{0.100} \\
\hline & Test & 0.15 & 0.03 & 0.22 & \\
\hline
\end{tabular}

*: Significant at $P \leq 0.05$

\section{DISCUSSION}

The prevention of tooth decay and the treatment of initial lesions and cavities are ongoing challenges in dentistry. Recently, biomimetic approaches have been used to develop nanomaterials for inclusion in different oral health-care products. Therefore, commercially available n-HAp containing toothpastes are increasing day after day following the ongoing development in the field of nanotechnology and its dental applications. However, the presence of these products over shelves facilitates their wide use even among population not suffering from hypersensitive, high caries index or receiving an orthodontic treatment. Therefore, the current study was conducted to evaluate the effect of n-HAp containing toothpaste on the long term (up to one year) on the surface composition and nanomechanical properties of human enamel.

The rationale for adding the n-HAp powder to conventional commercially available toothpaste rather than the use of commercially available n-HAp containing one was first, to certify the 
presence of $10 \mathrm{wt}$ \% n-HAp that has been found to be the lowest percentage that provides effective enamel remineralization ${ }^{5}$. Second, to standardize the toothpastes used in the current study i.e. to make sure that the only difference that would occur will be due to the effect of the added n-HAp powder rather than any change in the composition offered by using control group with conventional toothpaste and a test group with a commercial toothpaste containing n-HAp powder.

The authors tried to simulate the oral conditions as far as was applicable in this in vitro study design. The toothpaste/artificial saliva slurry was freshly prepared daily and the brushing was done under standardized force of $200 \mathrm{~g}$ that represent the average brushing force ${ }^{12}$. Brushing was performed for 1 hour/day for 24 days in order to simulate the clinical use of the toothpaste for 1 year i.e. brushing 2 times/day or 4 minutes ${ }^{12}$. Furthermore, the measurement of the $\mathrm{pH}$ value of the freshly prepared slurries and during the brushing time was performed to screen out if the addition of the n-HAp powder to the commercial toothpaste affects the $\mathrm{pH}$ value of the slurry as this could affect the remineralization process. Actually, the $\mathrm{pH}$ of the $\mathrm{n}-\mathrm{HAp}$ containing toothpaste/artificial saliva slurry was the same as that of the control toothpaste/ artificial saliva slurry. This means that under the controlled brushing conditions used any difference in the properties of the test group would be related to the effect of the nano-size of the added HAp powder rather than the change in the $\mathrm{pH}$ value.

The null hypothesis in this in vitro study was partially rejected. As the results of the current study revealed that the enamel surface chemical composition and nanohardness values were not significantly different after simulated brushing with 10 wt. \% n-HAp standardized toothpaste (test group) for one year as compared with the control group (Tables 1,3). On the other hand, the enamel elastic modulus of the test group was significantly higher than that of the control group as seen in table 2. This could be attributed to the fact that hardness is mainly a surface property while the elastic modulus is a bulk property related the composition ${ }^{16}$.

It is well known that human enamel is composed of $96 \%$ inorganic component and at least 4 wt. \% of organic tissues and water ${ }^{17}$. The apatite crystals in human (biologic) enamel that made the main part of the inorganic component are highly defective and contain at least 2 wt. $\%$ carbonate ions ${ }^{18}$. These 2 features cause a decrease in the elastic modulus of human enamel ${ }^{19}$. The elastic modulus results of the current study are in agreement with Habelitz et al. in $2001{ }^{9}$. They reported lower elastic moduli values for biologic enamel as compared to those for pure single hydroxy- or fluoro-apatite crystals. Hence, inclusion of biological contaminants, such as protein, influences the properties of enamel ${ }^{20}$. Additionally, the values of the elastic modulus obtained in the present study for the control group were in agreements with previous studies ${ }^{10,21}$.

Moreover, the SEM imaging of the enamel surface brushed with $10 \mathrm{wt}$ \% n-HAp standardized toothpaste confirmed the presence of newly formed n-HAp layer of 4-5 $\mu \mathrm{m}$ thickness (Figs.2, 4). The entire enamel surface was covered with finely divided particles with a size range of approximately 14-84 $\mathrm{nm}$ that coalesce and form a new surface layer of nanostructure (Fig. 2). It appeared that n-HAp sediment onto the enamel surfaces and directly filled up any surface defects. On the other hand, the SEM of the enamel surface in the control group appeared homogenous without any identification of newly precipitated structures (Fig.3). Side view of the vertically sectioned specimens revealed the thickness $(\sim 5 \mu \mathrm{m})$ of the well-defined newly precipitated n-HAp layer on the enamel surface after the simulated brushing with the 10 wt. \% n-HAp standardized toothpaste for one year (Fig.4). At higher magnifications, a well-defined needle like shaped crystals of n-HAp was detected in the test 
group in contrast to the control group (Figs. 5 and 6 respectively).

Although, the synthetic apatite crystals are much harder than enamel, in the current study the enamel nanohardness values after the simulated one year of brushing with 10 wt. \% n-HAp standardized toothpaste (4.2 GPa) were not statistically significantly different than the control group (2.4 GPa). This may be attributed to the fact that nanoindentation test was performed superficially (500 $\mathrm{nm}$ in depth). This means that during indentation of the test group the hardness of the newly precipitated n-HAp layer was measured as the whole thickness of the precipitated layer is about $5 \mu \mathrm{m}(5000 \mathrm{~nm})$. In spite of the defective nature of the apatite crystals in biologic enamel as mentioned earlier (control group), such superficial indentation could be only within the prismless enamel which occurs in the outermost $30 \mu \mathrm{m}$ of enamel. This prismless enamel has been observed in all deciduous teeth and in $70 \%$ of permanent teeth. No prism outline is visible and the hydroxyapatite crystals are parallel to each other and perpendicular to the surface. Such layer is heavily mineralized than the bulk of the enamel beneath it ${ }^{22}$. This has been furtherly supported by the insignificant differences in enamel surface chemical composition among the control and test groups as seen in table 3 . However, these findings confirmed that the modulus of elasticity is more sensitive to any minor change in surface enamel nano-structure and composition rather than the hardness.

It worth empathize that higher elastic modulus of enamel could be reflected clinically as unfavorable mechanical response to forces in the complex nature of the oral cavity. Therefore, in spite of the statistical significance differences between the enamel elastic modulus of the test group (117.5 $\mathrm{GPa}$ ) and that of the control group (92.6 GPa), the clinical significance is mandatory to be studied under simulated oral conditions. Consequently, the increased use of oral products containing $\geq 10 \mathrm{Wt}$. $\%$ n-HAp should be limited to patients with high susceptibility to demineralization or suffering from hypersensitivity until more clinically related studies are conducted.

The nanoindentation test was used in the present study as it is a reliable method to study the nanomechanical alterations of mineralized tissues 9, 23-26. The nanoindenter test is essentially a nondestructive method; since the indentations that are made are only visible with a high power optical or atomic force microscope (AFM) ${ }^{27}$. This depthsensing technique permitted the measurement of hardness and elastic modulus of hard tissues in very small submicrometer areas $\left(<1 \mu \mathrm{m}^{2}\right)^{9,15}$. The nanoindenter is capable of applying loads in the range of 0.1 to $5000 \mathrm{mgf}$ while simultaneously measuring displacement changes $<1 \mathrm{~nm}$, hence accounting for both plastic and elastic deformation, as well as time dependent effects 9,14,15,24. This was considered a major advantage compared to earlier studies, which used Knoop or Vickers microhardness testing ${ }^{28},{ }^{29}$. However, due to the combined effect of the extremely small size of the indenter tip and the low magnitude of the applied load, the tip of the indenter could hit an enamel sheath rather than an enamel rod. This has been reflected on the range of the measured nano-mechanical properties in the current study. The minimum values obtained for the nano-hardness (1.1 GPa) and enamel elastic modulus (48.9 Gpa) were in accordance with a previous study performed by Ge J. et al. in 2005, where these values were recorded for the enamel sheath as confirmed by the AFM ${ }^{30}$.

Further research work is recommended for studying whether the newly precipitated nanohydroxyapatite layer on enamel surface would have any effect on enamel surface roughness with its subsequent color stability and bonding ability to various restorative materials. 


\section{CONCLUSIONS}

Within the limitations of the current in vitro study, the following conclusions could be withdrawn: first, simulated use of toothpaste standardized by $10 \mathrm{wt}$. $\%$ n-HAp for one year precipitated n-HAp layer on enamel surface. Second, The newly precipitated n-HAp layer did not affect the enamel nanohardness but increased its elastic modulus, and third, the routine use of dental products like toothpastes containing $\geq 10 \mathrm{wt} . \%$ of n-HAp; should be restricted to those patient susceptible to demineralization or after orthodontic treatment; to avoid their possible negative effect on enamel elastic modulus at the nanoscale that could be reflected clinically on the longevity of the teeth and their mechanical behavior in the oral cavity.

\section{ACKNOWLEDGEMENT}

The authors acknowledge Eng. Ahmed El- Ghazally, the Yousef Jameel Science and Technology Research Center, School of Sciences and Engineering, The American University in Egypt for performing the nanoindentation test. Additionally, the authors acknowledge Geologist Mr. Adel Bioummy, The Ministry of Petroleum, The Egyptian Mineral Resources Authority, Central Laboratory Sector for SEM imaging and EDXA analysis.

\section{REFERENCES}

1. Oliveria M, Mansur HS. Synthetic tooth enamel: SEM characterization of fluoride hydroxyapatite coating for dentistry application. Mater Res 10: 115-118, 2007.

2. Liu C, Wang W, Shen W, Chen T, Hu I, Chen Z. Evaluation of the biocompatibility of nonceramic hydroxyapatite. $\mathrm{J}$ Endod 23: 490-493, 1997.

3. Moshaverinia A, Ansari S, Moshaverinia M, Roohpour N, Darr JA, Rehman I. Effects of incorporation of hydroxyapatite and fluoroapatite nano-bioceramics intoconventional glass ionomer cements (GIC). Acta Biomater 4: 432-440, 2008.
4. Pepla E, Besherat LK, Tenore G, Migliau G. Nanohydroxyapatite and its application in preventive, restorative and regenerative dentistry: a review of literature. Ann Stomatol 3: 108-114, 2014.

5. Huang SB, Gao SS, Yu HY. Effect of nano-hydroxyapatite concentration on remineralization of initial enamel lesion in vitro. Biomed Mater 4: 1-6, 2009.

6. Huang S, Gao S, Cheng L, Yu H. Combined effects of nanohydroxyapatite and Galla chinensis on remineralisation of initial enamel lesion in vitro. $J$ Dent 38: 811-819, 2010.

7. Tschoppe P, Zandim DL, Martus P, Kielbassa AM. Enamel and dentin remineralization by nano-hydroxyapatite toothpastes. J Dent 39: 430-437, 2011.

8. Cohen SR, Apter N, Jesse S. AFM investigation of mechanical properties of dentin. Isr J Chem 48: 65-72, 2008.

9. Habelitz S, Marshall SJ, Marshall GW, Balooch M. Mechanical properties of human dental enamel on the nanometre scale. Arch Oral Biol 46: 173-183, 2001.

10. Zhang YR, Du W, Zhou X-D Yu H-Y. Review of research on the mechanical properties of the human tooth. Int J Oral Sci 6: 61-69, 2014.

11. Li H, Zhoua ZR. Wear behavior of human teeth in dry and artificial saliva conditions. Wear 249: 980-984, 2002.

12. Heintze SD, Forjanic. M, Ohmiti, K, Rousson V: Surface deterioration of dental materials after simulated tooth brushing in relation to brushing time and load. Dent Mater 26: 306-319, 2010.

13. Azer SS, Machado C, Sanchez E, Rashid R. Effect of bleaching on enamel nanohardness and elastic modulus. J Dent 37: 185-190, 2009.

14. Huja SS, Beck FM, Thurman DT. Indentation properties of young and old osteons. Calcif Tissue Int 78: 392-397, 2006.

15. Oliver WC, Pharr GM. An improved technique for determining hardness and elastic modulus using load and displacement sensing indentation experiments. J Mater Research 7: 1564-1583, 1992.

16. Powers JM, Sakaguchi RL. Craig's Restorative Dental Material: 12th ed., Missouri: Mosby, Elsevier Science Publishing Co., 11830 Westline Industrial drive, P.84, 2006. 
17. Gutiérrez-Salazar MP, Reyes-Gasgaa J. Microhardness and Chemical Composition of Human Tooth. Mater Res 6: 367-373, 2003.

18. Teraoka K, Ito A, Maekawa K, Onuma K, Tateishi T, Tsutsumi S. Mechanical properties of hydroxyapatite and OH-carbonated hydroxyapatite single crystals. J Dent Res 77: 1560-1568, 1998.

19. Sakaguchi RL, Powers JM: Craig's Restorative Dental Material: 13th ed., Missouri: Mosby, Elsevier Science Publishing Co., 11830 Westline Industrial drive, P.9, 2012.

20. White SN, Luo W, Paine ML, Fong H, Sankaya M, Snead ML. Biological organization of hydroxyapatite crystallites into a fibrous continuum toughens and controls anisotropy in human enamel. J Dent Res 80: 321-326, 2001.

21. He LH, Fujisawa N, Swain MV. Elastic modulus and stressstrain response of human enamel by nano-indentation. Biomater 27: 4388-4398, 2006.

22. Nanci A. Ten cate's Oral histology, development, structure and function, 8 th ed,. Mosby, Elsevier, 122-128, 2013.

23. Cuy JL, Mann AB, Livi KJ, Teaford MF, Weihs TP. Nanoindentation mapping of the mechanical properties of human molar tooth enamel. Arch Oral Biol 47:281-291, 2002.
24. Ge J, Cui FZ, Wang XM, Feng HL. Property variations in the prism and the organic sheath within enamel by nanoindentation. Biomater 26:3333-3339, 2005.

25. Bao YW, Wang W, Zhou YC. Investigation of the relationship between elastic modulus and hardness based on depth-sensing indentation measurements. Acta Mater 52:5397-5404, 2006.

26. Oyen ML. Nanoindentation hardness of mineralized tissues. J Biomech 39:2699-2702, 2006.

27. Xu HHK, Smith DT, Jahanmir S, Romberg E, Kelly JR, Thompson VP, Rekow ED. Indentation damage and mechanical properties of human enamel and dentin. J Dent Res 77:472-480, 1998.

28. Rodrigues JA, Marchi GM, Ambrosano GMB, Heymann HO, Pimenta LA. Microhardness evaluation of in situ vital bleaching on human dental enamel using a novel study design. Dent Mater 21:1059-1067, 2005.

29. Attin T, Vollmer D, Wiegand A, Attin R, Betke H. Subsurface microhardness of enamel and dentin after different external bleaching procedures. Am J Dent; 18: 8-12, 2005.

30. Ge J, Cui FZ, Wang XM, Feng HL. Property variations in the prism and the organic sheath within enamel by nanoindentation. Biomater; 26 :3333-3339, 2005. 